\title{
Successful surgical treatment of a ruptured giant atherosclerotic aneurysm of arcus aorta
}

\author{
Barış Akça ${ }^{1}$, Nevzat Erdil'², Olcay Murat Dişli ${ }^{3}$, Mehmet Cengiz Çolak ${ }^{2}$, Bektaş Battaloğlu
}

\footnotetext{
1) İnönü University School of Medicine, Department of Cardiovascular Surgery, Ass. Dr., Malatya, Turkey.

2) İnönü University School of Medicine, Department of Cardiovascular Surgery, Prof. Dr., Malatya, Turkey.

3) İnönü University School of Medicine, Department of Cardiovascular Surgery, Asst. Assoc. Dr., Malatya, Turkey.
}

\begin{abstract}
Endovascular aortic repairs in hybrid theatres have been implemented as an alternative option for the treatment of aortic arch aneurysms. The improvements in synthetic graft technologies, cardiopulmonary bypass techniques, blood protection, myocardial protection and protection of the central nervous system have resulted in safer applications of surgical interventions, particularly to the arcus aorta. In this article, we present our successful emergency surgical therapeutic approach in a 74-year-old female patient case with a ruptured giant aortic arch aneurysm.
\end{abstract}

Key words: Endovascular aortic repairs, aortic arch aneurysms, arcus aorta.

Akça B., Erdil N., Dişli O. M., Çolak M. C., Battaloğlu B. Successful surgical treatment of a ruptured giant atherosclerotic aneurysm of arcus aorta EJCM 2017; 05 (4): 75-78. Doi: 10.15511/ejcm.17.00475. 


\section{Introduction}

Due to its high mortality and morbidity rates, the surgical treatment for aortic arch aneurysms is challenging,${ }^{(1)}$ although there is currently a lack of consensus on the optimal treatment modality in the high-risk patients. Recently, endovascular aortic repairs in hybrid theatres have been implemented as an alternative option for the treatment of aortic arch aneurysms..$^{(1)}$ The improvements in synthetic graft technologies, cardiopulmonary bypass techniques, blood protection, myocardial protection and protection of the central nervous system (particularly selective cerebral perfusion and hypothermic circulatory arrest) have resulted in safer applications of surgical interventions, particularly to the arcus aorta. ${ }^{(2-5)}$ In this article, we present our successful emergency surgical therapeutic approach in a female case with a ruptured giant aortic arch aneurysm.

\section{Case Report}

A 74-year-old female patient was admitted to our emergency clinic with complaints of blurred consciousness, chest pain and dyspnea. A physical examination of arterial blood pressure, pulse and oxygen saturation revealed values of $80 / 40 \mathrm{mmHg}, 122$ beats/min and 85 $90 \%$, respectively. On auscultation of the left hemithorax, breath sounds decreased, and a chest X-ray revealed a giant aortic aneurysm and opacity in the left hemithorax that was suggestive of a pleural effusion (Figure 1A).
A true saccular aortic arch aneurysm that was measured $8 \times 6 \mathrm{~cm} 2$ which had ruptured into the left hemithorax was detected in a contrasted thoracoabdominal tomography (Figure 2A, 2B).

Written informed consent was obtained from the patient's relatives, and the patient who underwent emergency surgery. The left lung was adhered to the pleura, and the aortic arch was extremely atherosclerotic. A substantial amount of hematoma was present in the left thorax. A cardiopulmonary bypass was performed using the cannulation of the right axillary artery.

The patient was cooled to $25^{\circ} \mathrm{C}$ and aneurysmal sac opened by applying circulatory arrest under the right selective antegrade cerebral perfusion. An anastomosis of a 30-mm Hemashield graft (Maquet, France) was applied to the descending aorta, and the branches of the arcus were implanted onto the grafts cutting in the form of islets. The graft was then clamped, and a total bypass was applied. The total aortic arch replacement was completed through the graft anastomosis with the ascending aorta during the heating phase. The cardiopulmonary bypass was uneventful. The incisions were closed after bleeding management, and the patient was transferred to the Intensive Care Unit (ICU). She recorded no hemodynamic or neurological problems in her post-operative followup, although she was unable to tolerate extubation during the ICU stay (in the postoperative 10th hour), and she was re-intubated due to pulmonary complications.

Figure 1A - 1B

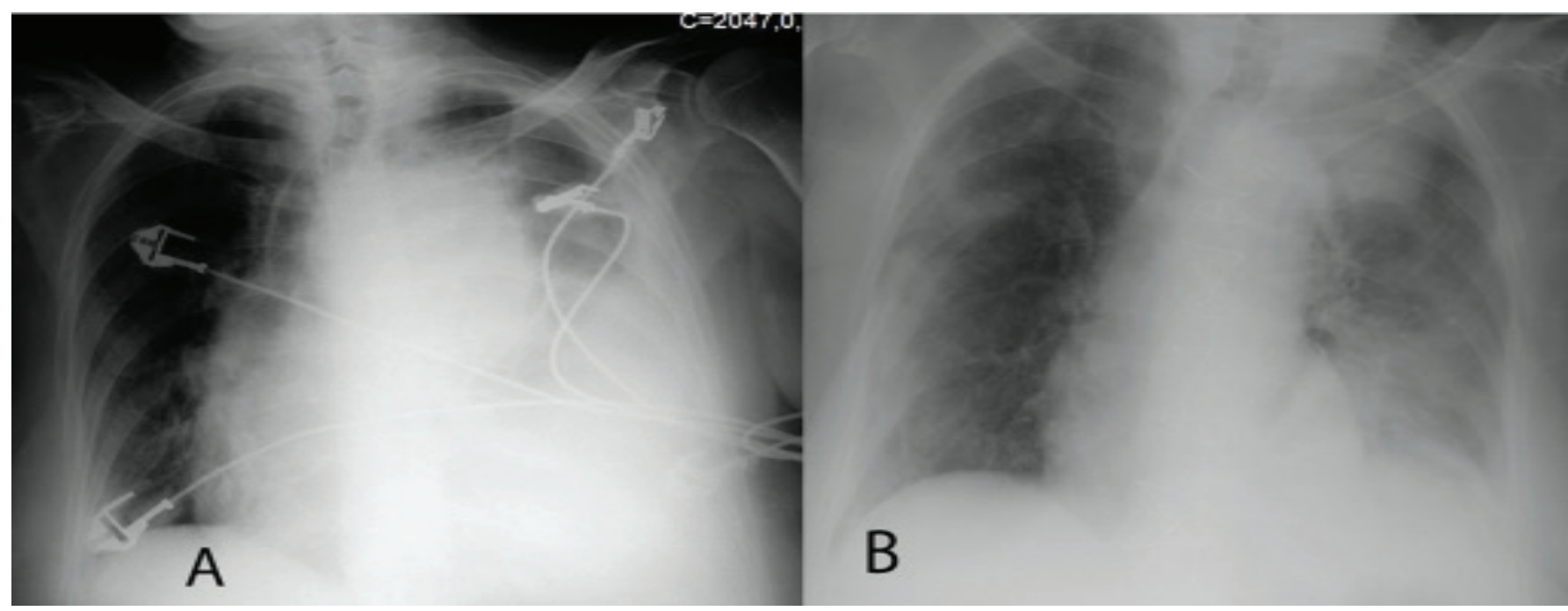


The patient was then transferred to the Anesthesiology and Reanimation Clinic and was extubated by administering a successful ICU program (Figure 1B). She experienced no problems following extubation, and she was discharged on the 15 th postoperative day.

\section{Discussion}

Aortic ruptures, as a complication of aortic aneurysms, leads to massive bleeding with a high rate of mortality. An emergent diagnosis and treatment following a multidisciplinary approach can lead to successful outcomes, despite high mortality rates, as in our case.

With the developments in technological methods and increased surgical experience over the past two decades, successful therapeutic results have been reported in patients with aortic aneurysms. ${ }^{(6)}$ Applications of minimally invasive endovascular methods that can be performed via small inguinal incisions rather than thoracal aortic interventions through major surgical incisions have been rapidly increasing in recent years. ${ }^{(7)}$ Hybrid methods and conventional open surgery have been compared in a study that investigated aortic arch interventions, and higher technical success rates with reduced mortality rates have been reported with the application of hybrid methods in a certain high-risk patient group. ${ }^{(1)}$
Previous reports of hybrid arch procedures showed an early mortality rate of $7.4-23.7 \%$ with an incidence of stroke seen in $0-13.1 \% .^{(1,8)}$ In a meta-analysis with 463 patients who underwent hybrid arch surgery, the authors reported a 30 -day mortality rate of $8.3 \%$ with an incidence rate of stroke and paraplegia of 4.4 and 3.9\%, respectively. ${ }^{(9)}$

Endovascular treatments can be administered in cases of thoracic aortic disease that require a surgical approach if open surgery is considered to be a particularly high risk and if the anatomical appearance is appropriate. Our case was subjected to an open surgical intervention due to her presentation with hemodynamic instability and poor clinical status on emergency admission. Furthermore, there was no opportunity to make an endovascular intervention at the time of her admission, and an urgent intervention was needed.

In previous studies, it has been suggested that no definitive evidence exists that supports the superiority of hybrid thoracic endovascular aortic repair (TEVAR) over open arch repair, ${ }^{(10)}$ although most cases of hybrid TEVAR are in high-risk patients who are ineligible for conventional open aortic repair. In this respect, comparing and interpreting the results can be challenging. Further prospective, randomized controlled trials are required to

Figure 2A-2B

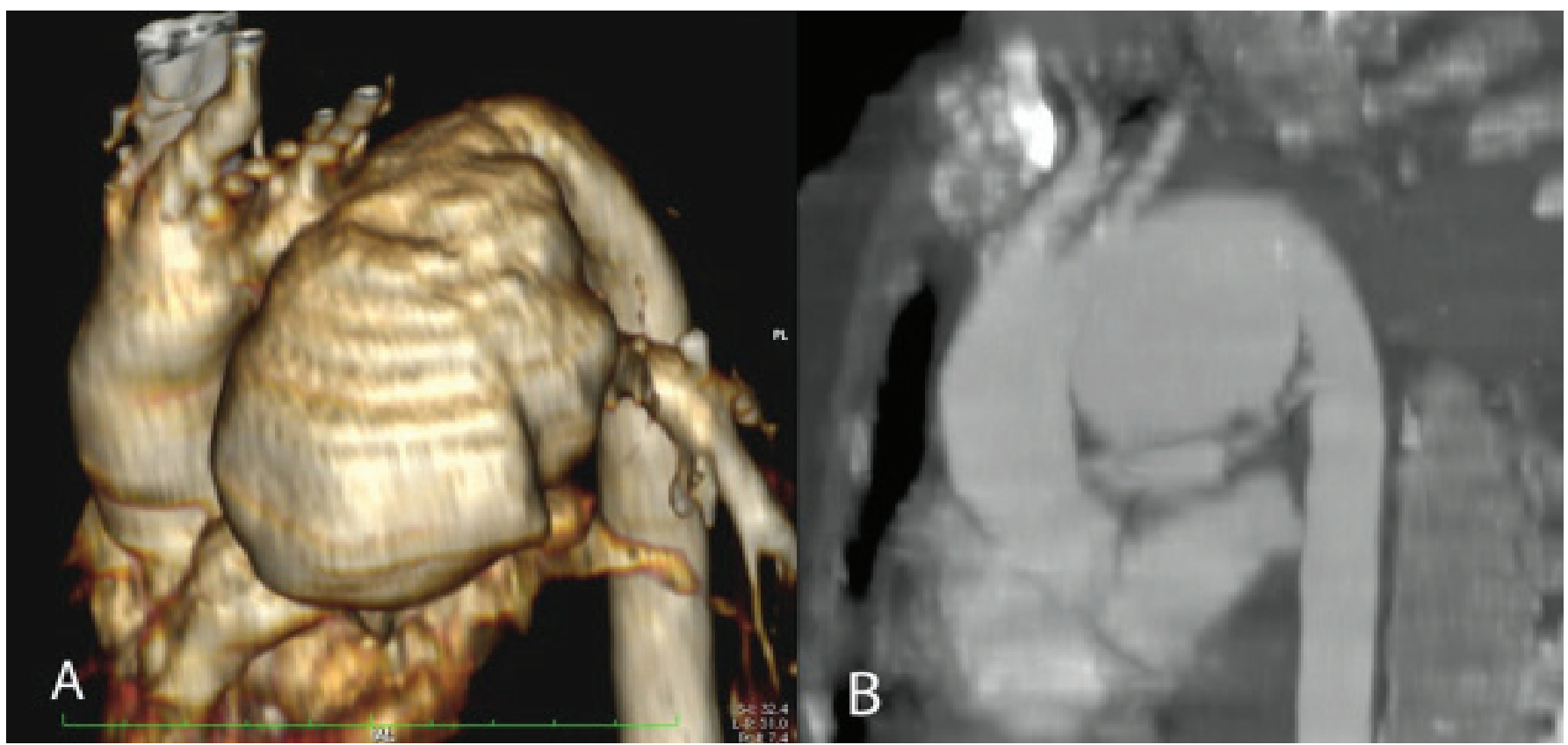

Akça B., Erdil N., Dişli O. M., Çolak M. C., Battaloğlu B. Successful surgical treatment of a ruptured giant atherosclerotic aneurysm of arcus aorta EJCM 2017; 05 (4): 75-78. Doi: 10.15511/ejem.17.00475. 
compare the outcomes of both surgical strategies.

In conclusion, although the recent outcomes of open arch repair and hybrid TEVAR demonstrate acceptable results, particularly early after the procedure, open arch

\section{References}

1. Milewski RK, Szeto WY, Pochettino A, Moser GW, Moeller P, Bavaria JE. Have hybrid procedures replaced open aortic arch reconstruction in high-risk patients? A comparative study of elective open arch debranching with endovascular stent graft placement and conventional elective open total and distal aortic arch reconstruction. J Thorac Cardiovasc Surg 2010;140(3):590-7.

2. Bachet J, Guilmet D, Goudot B, Dreyfus GD, Delentdecker P, Brodaty $\mathrm{D}$ et al. Antegrade cerebral perfusion with cold blood: a 13-year experience. Ann Thorac Surg 1999;67:1874-8.

3. Kazui T, WashiyamaN, Muhammad BA, Terada H, Yamashita K, Takinami $\mathrm{M}$ et al. Total arch replacement using aortic arch branched grafts with the aid of antegrade selective cerebral perfusion. Ann Thorac Surg 2000;70:3-9.

4. Kazui T, Yamashita K, Washiyama N, Terada H, Bashar AH, Suzuki K et al. Aortic arch replacement using selective cerebral perfusion. Ann Thorac Surg 2007;83:S796-8.

5. Zierer A, Detho F, Dzemali O, Aybek T, Moritz A, Bakhtiary F. Antegrade cerebral perfusion with mild hypothermia for aortic arch replace- repair can bring more reliable outcomes during followup. These two surgical strategies, when properly selected based on the individual risk, can improve surgical outcomes in patients with aortic arch aneurysms, especially in ruptured cases. ment: single-center experience in 245 consecutive patients. Ann Thorac Surg 2011;91:1868-74.

6. Coselli JS, LeMaire SA. Tips for successful outcomes for descending thoracic and thoracoabdominal aortic aneurysm procedures. Semin Vasc Surg 2008;21:13-20.

7. Donas KP, Czerny M, Guber I, Teufelsbauer H, Nanobachvili J. Hybrid open-endovascular repair for thoracoabdominal aortic aneurysms: current status and level of evidence. Eur J Vasc Endovasc Surg 2007;34:528-33.

8. Vallejo N, Rodriguez-Lopez JA, Heidari P, Wheatley G, Caparrelli D, Ramaiah $\mathrm{V}$ et al. Hybrid repair of thoracic aortic lesions for zone 0 and 1 in high-risk patients. JVasc Surg 2012;55:318-25.

9. Koullias GJ, Wheatley GH III. State-of-the-art of hybrid procedures for the aortic arch: a meta-analysis. Ann Thorac Surg 2010;90:689-97.

10. Benedetto U, Melina G, Angeloni E, Codispoti M, Sinatra R. Current results of open total arch replacement versus hybrid thoracic endovascular aortic repair for aortic arch aneurysm: a meta-analysis of comparative studies. J Thorac Cardiovasc Surg 2013;145:305-6.

Received: 29/07/2017

Accepted: 18/11/2017

Published: 15/12/2017

Disclosure and conflicts of interest:

Conflicts of interest were not reported.

\section{Corresponding author:}

Dr. Barış Akça

Mail: dr.baris.akca@yandex.com.tr 